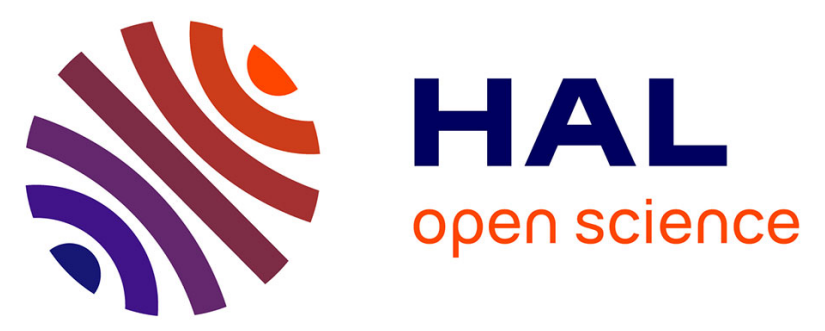

\title{
Reactivity of nanocolloidal particles -Fe2O3 at the charged interfaces Part 1. The approach of particles to an electrode
}

\author{
Ivan T. Lucas, Emmanuelle Dubois, Jean Chevalet, S. Durand-Vidal
}

\section{- To cite this version:}

Ivan T. Lucas, Emmanuelle Dubois, Jean Chevalet, S. Durand-Vidal. Reactivity of nanocolloidal particles -Fe2O3 at the charged interfaces Part 1. The approach of particles to an electrode. Physical Chemistry Chemical Physics, 2008, 10, pp.3263 - 3273. 10.1039/b718593f . hal-00288442

\section{HAL Id: hal-00288442 \\ https://hal.science/hal-00288442}

Submitted on 17 Jun 2008

HAL is a multi-disciplinary open access archive for the deposit and dissemination of scientific research documents, whether they are published or not. The documents may come from teaching and research institutions in France or abroad, or from public or private research centers.
L'archive ouverte pluridisciplinaire HAL, est destinée au dépôt et à la diffusion de documents scientifiques de niveau recherche, publiés ou non, émanant des établissements d'enseignement et de recherche français ou étrangers, des laboratoires publics ou privés. 


\title{
Reactivity of nanocolloidal particles $\gamma-\mathrm{Fe}_{2} \mathrm{O}_{3}$ at the charged interfaces: 1-Approach.
}

\author{
I. T. Lucas ${ }^{* a}$, E. Dubois ${ }^{\mathrm{a}}$, J. Chevalet ${ }^{\mathrm{a}}$ and S. Durand-Vidal ${ }^{\mathrm{a}}$
}

Received (in XXX, XXX) 1st January 2007, Accepted 1st January 2007

First published on the web 1st January 2007

\begin{abstract}
We are interested here in the reactivity of magnetic nanoparticles at the electrodeelectrolyte interface with the aim of the electrochemical synthesis of magnetic and conductive liquids (electronic conduction). The reactivity of charged colloidal particles occurs through a two steps process, the first being the approach toward the electrode with a possible adsorption phenomenon and the second step, the electron transfer. In this first paper we focus on the approach and the deposition of well-defined $\gamma-\mathrm{Fe}_{2} \mathrm{O}_{3}$ nanoparticles onto conductive substrates like mercury and gold under different conditions in order to vary the interactions particle/substrate especially the electrostatic interactions. The approach of the particles near the electrodes is estimated from the electrochemical currents related to the transformation of the particles. This electrochemical method is validated by coupling several techniques on gold electrodes: direct imaging by Atomic Force Microscopy and study of kinetics by reflectometry. The results show that the electrochemical currents are always associated to adsorption of the particles, so that the electrochemical method can be used to estimate the adsorption of the particles, thus to follow the kinetics. The influence of the electrostatics on the occurrence of adsorption highly depends on the nature of the substrate and on the nature of the colloidal suspension. (ions, $\mathrm{pH}$, ionic strength), whereas electrostatics governs the deposits in some cases, it is totally dominated by other interactions in other cases. Therefore, it seems difficult to predict a priori the existence of adsorption. However, when a deposit occurs, the kinetics and the maximal coverage of the substrates are controlled by the electrostatic interactions between the particles already adsorbed and those, close to the interface, in the bulk of the solution.
\end{abstract}

\section{I- Introduction}

This work deals with the approach and the adsorption process of charged nanoparticles in solution onto charged surfaces with the aim of studying their electrochemical transformation. The approach of the charged particles toward the charged surface precedes adsorption, however the step of approach is seldom precisely considered and studied although it is essential ${ }^{1,2}$ in the purpose of studying the electrochemical transformations of the nanoparticles. The second step of adsorption is usually considered, indeed adsorption phenomena of particles onto substrate is a general purpose of interest involved in natural phenomena like thrombosis or biofooling of membrane, but it also finds application in techniques as chromatography or micro filtration ${ }^{3}$. It is commonly admitted that the adsorption depends on the balance between short (van der Waals forces) and long range interactions (electrostatic forces in aqueous medium) between the charged substrate and the particles and also of hydrodynamic forces and thermal motion. The determination of the real contribution of each of these forces, in particular the electrostatic interactions, is the purpose of many works. These electrostatic interactions occur both between bulk particles with charged surfaces and also with already adsorbed particles. The case of particles in the nanometer size range is interesting because the range of the electrostatic interactions given by the Debye parameter $\kappa^{-1}$ can be of the same order as the diameter of the particles. Consequently, one could expect that the contribution of the electrostatic interactions in the deposition process is more marked for small particles than for bigger ones.

In the literature, as authors are interested in the deposition, they use conditions supposed to allow the approach, typically using substrates and particles of opposite signs. Otherwise, no adsorption takes place as usually reported. Consequently, to make the adsorption possible, authors usually control the sign either of the particles with surfactant $\left(\mathrm{CTAB}^{4}\right)$ or of the substrate by adsorption of polyelectrolyte $\left(\mathbf{P V I}^{5}\right.$ and APTES ${ }^{6,7}$ onto oxidized silicon, DETA onto glass ${ }^{8}$, poly-L-lysine onto mica ${ }^{9}$ ) or chemical treatment (mica with $\mathrm{AlCl}_{3}{ }^{10}$ ). On the one hand, the deposition of particles becomes possible, on the other hand the adsorption becomes irreversible, this latter condition being necessary to study kinetics of deposition of the particles. Most of the studies concern the deposition of particles in the 
micrometer size range like latex ${ }^{11,12}$ and silicon oxides particles ${ }^{13,14,15}$ onto substrates as mica, gold, glass and silicon. Optical microscopy is used to study the deposition of such particles and is usually coupled to an impinging jet cell ${ }^{16}$ that allows controlling the hydrodynamic conditions during the deposition process. For smaller particles $(\mathrm{d}<100 \mathrm{~nm})$ optical microscopy is no longer efficient and other techniques, as reflectometry and scanning probe microscopy, have to be implemented. Reflectometry, that is based on the variation of the refractive index near the substrate when particles adsorb, proved to be very convenient to study adsorption kinetics ${ }^{11,12,17,18,19}$ of the particles but it has to be coupled with atomic force microscopy (AFM) to probe the structure and the organisation of the adsorbed layers ${ }^{20,21}$. Recently, thanks to the improvement of reflectometric techniques, a few works were interested in the adsorption of poly-electrolytes ${ }^{22,23,24}$ and also of particles in the size range $\mathrm{d}=5-20 \mathrm{~nm}^{25,13}$.

All of these studies raised the importance of the repulsive interactions between bulk particles and already adsorbed particles onto the substrate and the importance of the ionic strength (I) and of the $\mathrm{pH}$ that determine the range and the magnitude of these interactions. But only a few work, which concern the adsorption of polyelectrolyte onto gold ${ }^{22,26,27}$, are interested in the influence of the interactions between the substrates and the particles. Their results did not reveal a clear dependence between the charge of the substrate and the possibility for polyelectrolyte to adsorb.

In this work we present a study of the adsorption of well-defined iron oxides $\left(\gamma-\mathrm{Fe}_{2} \mathrm{O}_{3}\right)$ nanoparticles (12nm) onto several substrates, conductive (mercury and gold) or not conductive (mica). We probe in particular the influence of the charge (sign and magnitude) of the substrate that can be modified by varying the ionic strength, the $\mathrm{pH}$, the potential $\mathrm{E}$ applied in the case of conductive substrates, or by chemical derivatization of the substrates. If the electrochemical measurements are possible on gold and mercury, associated physical observations of the particles adsorbed by coupling AFM and reflectometry are only possible with gold electrodes. This association of techniques allows us to validate an original method based on the electrochemical conversion of the particles to estimate the adsorption rate of particles at the mercury and the gold electrode.

\section{II- Material and methods}

\subsection{System particles/substrate}

\section{Colloidal System}

The colloidal suspensions are composed of maghemite nanoparticles $\left(\gamma-\mathrm{Fe}_{2} \mathrm{O}_{3}\right.$ : a magnetic iron oxide) that are chemically synthesized ${ }^{28}$. Briefly, magnetite nanoparticles $\mathrm{Fe}_{3} \mathrm{O}_{4}$ are obtained in a first step by coprecipitation of ferrous and ferric ions in alkaline medium. Then particles are chemically oxidized to maghemite by ferric nitrate in nitric acid. The size of the resulting colloid, after reduction of the size polydispersity ${ }^{29}$, is determined by AFM measurements performed in the oscillating mode (see Figure 1a). The inset (Zoom 100nm x80nm) emphasizes the convolution effect on $x, y$ axis. A cross section of the AFM image in the inset on Figure 1b, allows to visualise the real size of the particles on the $\mathrm{z}$ axis. A counting of the number of particles adsorbed on several mica substrates $\left(4 \mu \mathrm{m}^{2}\right)$ as a function of $\mathrm{z}$ allows obtaining the particles size distribution. The solid line represents a $\log$ normal fit to the histogram with a mean diameter $\mathrm{d}_{\mathrm{o}}=12 \mathrm{~nm}$ (defined by $\ln \mathrm{d}_{\mathrm{o}}=\langle\ln \mathrm{d}\rangle$ ) and a polydispersity $\sigma=0.238$.

These particles of maghemite can be dispersed in $\mathrm{HNO}_{3}$ and are positively charged. The charge induces electrostatic repulsion forces between particles and allows stabilizing the suspensions if the conditions of $\mathrm{pH}$ and ionic strength are appropriate. Indeed, these two parameters determine the sign and the magnitude of the charge and also the range of the electrostatic interactions (effective charge). The dependence of the charge with the $\mathrm{pH}$ has been studied in detail by Lucas et $\mathrm{al}^{30}$. The charge of the particles is inherent to the presence of superficial acidic groups that exchange protons with the solution according to the equilibria (1) and (2).

$$
\begin{aligned}
& \mathrm{M}-\mathrm{OH}_{2}^{+}=\mathrm{M}-\mathrm{OH}+\mathrm{H}^{+} \\
& \mathrm{M}-\mathrm{OH}=\mathrm{M}-\mathrm{O}+\mathrm{H}^{+}
\end{aligned}
$$

Thus, due to the acidic properties of the superficial groups, the structural charge is positive in acidic medium, negative in alkaline medium; its magnitude is maximum at extreme $\mathrm{pH}$ values and falls down to 0 around $\mathrm{pH}=7$, the point of zero charge (PZC). At intermediate $\mathrm{pH}$ values $3.5<\mathrm{pH}<10.5$ the surface charge density of the particles is too low, and the colloidal suspension does not remain stable. One solution for obtaining a stable dispersion is to coat the surface with small citrate molecules in order to shift the point of zero charge ${ }^{31}$. Under such conditions the charge is negative for $\mathrm{pH}>3.5$. 


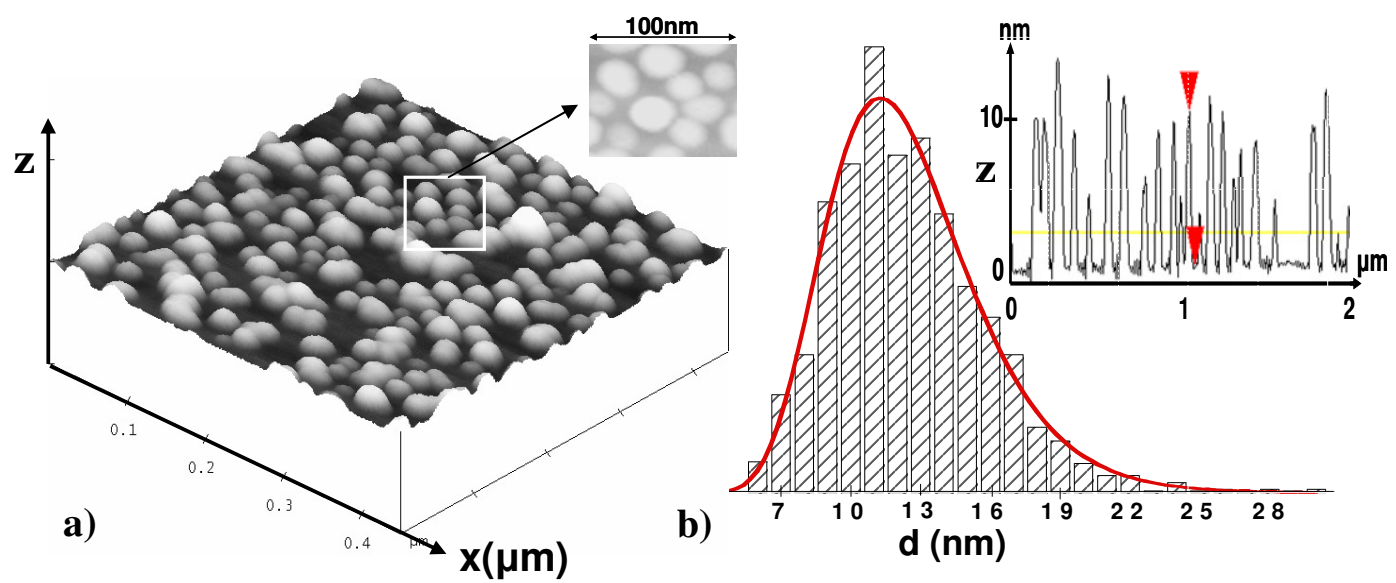

Figure 1: a) AFM image of maghemite nanoparticles adsorbed on mica substrates near saturation (Area: $500 \mathrm{~nm} \times 500 \mathrm{~nm}$ and zoom on an area of $100 \mathrm{~nm} \times 80 \mathrm{~nm}$ in the inset). b) size distribution of the particles and a cross section of the AFM image in the inset.

The stability depends on another crucial parameter, the nature of the counter ions:

- sodium $\left(\mathrm{Na}^{+}\right)$counter-ions, which are very small, destabilize the colloidal suspensions of negatively charged particles dispersed in alkaline medium. In acidic medium, divalent cations like sulphate $\left(\mathrm{SO}_{4}{ }^{2-}\right)$ screen the electrostatic interactions leading to the aggregation of the nanoparticles whereas univalent and bigger ions like nitrate $\left(\mathrm{NO}_{3}{ }^{-}\right)$or perchlorate ions $\left(\mathrm{ClO}_{4}^{-}\right)$are suitable.

- the particles dispersed in $\mathrm{HCl}$ are not stable because the kinetics of dissolution of the particles is very fast in the presence of ions $\left(\mathrm{Cl}^{-}\right)$which are complexing agents of iron. In perchloric or nitric acid, iron oxides are not thermodynamically stable below $\mathrm{pH}=1.5$ and start to dissolve, however the kinetics of dissolution is very slow.

- in the case of particles covered with citrate molecules associated with sodium counter-ions, it is necessary to maintain a citrate concentration in the solution greater than $3.10^{-3} \mathrm{~mol} \mathrm{~L}^{-1}$ in order to avoid the desorption of the citrate from the surface of the particle and the subsequent destabilization of the suspension.

In this study, dispersion of particles are realized in tetramethylammonium hydroxide $\left(\mathrm{TMA}^{+} \mathrm{OH}^{-}\right)$within the $10-13 \mathrm{pH}$ range, in an ammonium citrate solution within the $3.5-10 \mathrm{pH}$ range and in perchloric acid $\left(\mathrm{HClO}_{4}\right)$ between $\mathrm{pH}=1.0$ and $3.5^{30}$. Finally, ammonium perchlorate is added to the three types of suspension in order to modify the ionic strength at constant $\mathrm{pH}$ (from $10^{-3}$ to $10^{-1} \mathrm{~mol} \mathrm{~L}^{-1}$ ). At concentrations higher than $0.1 \mathrm{~mol} \mathrm{~L}^{-1}$, the electrostatic interactions between particles are so screened that the colloidal suspension flocculates. Consequently, our colloidal system is well characterized both from the point of view of its size and of its charge.

Substrates

Different types of substrates, non conductive and conductive are used, mica ("Metafix", Montdidier France) and gold respectively (ACM France). Mica, a natural charged substrate, is chosen because it is suitable for AFM measurements. The very low roughness of mica allows distinguishing particles in the nanometer size range adsorbed onto its surface; moreover by easy mechanical cleaving, perfectly cleaned surfaces can be obtained. The negative charge of the mica can be reversed to a positive one for $\mathrm{pH}<10$ after electrostatic adsorption of poly-L-lysine ( $\mathrm{pKa}$ lysine $=9.5$ thus the poly-L-lysine is uncharged for $\mathrm{pH}>10$ ). The derivatization is achieved by plunging the substrates into a $10^{-2} \%$ PolyL-Lysine $(0.1 \% \mathrm{w} / \mathrm{v}$ in water, Sigma-Aldrich) in water solution $(\mathrm{pH}=5.6)$ for $5 \mathrm{~min}$, a step followed by a thorough rinsing in milliQ water.

Gold is chosen as conductive substrate because it is electrochemically stable over a relatively wide range of applied potential $(-1.5 \mathrm{~V},+0.9 \mathrm{~V} / \mathrm{ECS}$ at $\mathrm{pH}=3)$. Moreover by using ultra flat gold surfaces, it becomes possible to correlate multiple techniques as AFM, reflectometry and the electrochemical measurements. We use here ultra flat gold surfaces with roughness lower than $0.5 \mathrm{~nm}$ and a thickness of gold around $15 \mathrm{~nm}$. This last parameter is very important because, in reflectometry, the light reflected by the particles adsorbed onto the gold surface can be detected if the absorbance of the gold layer is low enough, i.e. less than $20 \mathrm{~nm}$. The gold coated wafers are made according to the following process (ACM France): a thick layer of $\mathrm{SiO}_{2}$ is formed by thermal oxidation of the silicon wafer at $1000^{\circ} \mathrm{C}$ for one hour and then covered with titanium and gold. A thin layer of titanium is firstly deposited onto silicon in order to reduce the roughness of the surface and to increase the gold adhesion. The gold metallic-reflecting layer is then deposited by magnetron sputtering. The gold surfaces are cleaned thoroughly before their use, they are immersed first in cyclohexane and then in water in an ultrasonic bath for $15 \mathrm{~min}$, and are finally dried under nitrogen.

In parallel to the ultra flat gold surfaces, a polycrystalline gold working electrode (diameter $\mathrm{d}=1.5 \mathrm{~mm}$, embedded in a Teflon body) is used to carry out a rapid investigation of the electrochemical behaviour of the particles and finally to establish the kinetics of deposition of the particles onto gold. As for mica, the gold substrates can be derivatized with poly-L-Lysine for $\mathrm{pH}<10$. 
The control of the surface properties of the particles, and of the substrate (chemical modification, applied potential) allows us to explore different systems substrate/particle and therefore to observe the impact of the electrostatic interactions on the adsorption.

\subsection{Approach of the particle to the substrate: Methods of characterization}

\section{Atomic force microscopy}

AFM measurements performed on both non conductive and conductive substrates allow us to probe the presence of particles on the surfaces. AFM is not used to access the kinetics of deposition of the particles for two main reasons: (I) it is too long to get an acceptable statistic in order to determine the coverage as a function of the time (II) a very important convolution effect hinders accurate determination of the surface density of the adsorbed material at high coverage. This effect get worse due to the occurrence of a fast contamination of the AFM probe (silicon probe negatively charged) with particles positively charged while imaging.

Images are obtained using a "Digital Instrument Nanoscope III" system, operated in oscillating mode to reduce intrusive effect of the imaging process, employing silicon cantilevers with a typical resonance frequency of $300 \mathrm{KHz}$ (Nanosensors). Measurements in liquid (in situ) were not successful even in the oscillating mode. In fact, the intrusive effect of the imaging process on "physisorbed" particles is too important with respect to particles adhesion forces. That leads to lateral motion of these particles which are removed from the surface even if they are adsorbed onto polymer pre-treated surfaces. Consequently the substrates had to be rinsed and dried before AFM observations in air.

As crystals appear onto the surface during the drying step if the ionic strength of the rinsing solution is too high, the salt concentration has to be lower than $10^{-2} \mathrm{~mol} \mathrm{~L}^{-1}$ in order to optimize the quality of the AFM imaging.

\section{Electrochemical measurement}

We use here the electrochemical conversion properties of the particles to estimate the adsorption rate at the electrode especially at high coverage. Note that the nature of the electrochemical conversions is the purpose of another publication ${ }^{2}$. Voltammetric measurements are performed using the "Power lab station" from "ADinstrument Co", a working gold electrode is associated with a calomel or $\mathrm{Ag} / \mathrm{AgCl}$ reference electrode and with a platinum counter electrode. In practice, the gold substrates (ultra flat surfaces and the polycrystalline electrode) are electrically connected and placed in a home made electrochemical cell. The polycrystalline electrode is polished carefully with alumina $(0.05 \mu \mathrm{m})$, and then rinsed with water. Several electrochemical cycles are performed on both types of gold electrodes in dilute perchloric acid electrolyte until a reproducible current baseline is obtained. Voltammetric measurements on mercury are performed on a mercury drop (303A System from PAR EGG) with an $\mathrm{Ag} / \mathrm{AgCl}$ electrode and a Pt counter electrode.

\section{Reflectometry}

Reflectometric measurements are performed to access the kinetics of deposition, even at the very low coverage where the electrochemical method fails (the current measured being too low). The setup consists of a He-Ne laser, a stagnation point flow cell ${ }^{32}$, a gold coated silicon wafer and two photodiodes for detecting the relative intensities of the perpendicular $\left(\mathrm{I}_{\mathrm{p}}\right)$ and parallel $\left(\mathrm{I}_{\mathrm{s}}\right)$ components of a polarized light reflected at the interface. The stagnation point flow cell as described by Dijt et $\mathrm{al}^{32}$ and the fixed angle reflectometer are home built (Laboratoire de Chimie des Matériaux et Interfaces, university of Franche-Comté, France).

Due to the particle deposition, the refractive index profile close to the surface modifies the field components $\mathrm{E}_{\mathrm{rs}}$ and $E_{r p}$ of the reflected beam in a specific way. Measurements of the perpendicular and parallel light intensities $\left(I_{p}, I_{s}\right)$ given as the ratio $\mathbf{S}=\mathbf{I}_{\mathrm{p}} / \mathbf{I}_{\mathrm{s}}$ can be measured as a function of the relevant parameters (time $(\mathrm{t})$, particles concentration, $\mathrm{pH}$, ionic composition) and compared to the initial output $\mathbf{S}_{\mathbf{0}}=\left(\mathbf{I}_{\mathrm{p}} / \mathbf{I}_{\mathrm{s}}\right)_{\mathbf{0}}$ measured when the interface is free of particles. Given that $S$ varies linearly with the adsorbed amount $\boldsymbol{\theta}^{25}$, the relative changes in $\mathbf{S}\left(\boldsymbol{\Delta} \mathbf{S}=\mathbf{S}-\mathbf{S}_{\mathbf{0}}\right)$ can be related to $\boldsymbol{\theta}$ through the relationship $\left(\mathbf{S}-\mathbf{S}_{\mathbf{0}}\right) / \mathbf{S}_{\mathbf{0}}=\mathbf{A}_{\mathbf{s}} \cdot \boldsymbol{\theta}$ where $\mathrm{A}_{\mathrm{s}}$ is the sensitivity parameter defined as $\mathbf{A}_{\mathbf{s}}=\mathbf{1} / \mathbf{S}_{\mathbf{0}}$. dS/dt. To determine $\boldsymbol{\theta}$, the value of $\mathrm{A}_{\mathrm{s}}$ is needed. This necessitates the elaboration of a model to calculate the reflectivity of a layer of nanospheres ${ }^{15,33}$. This is not performed here and we are only interested in the variation of $\Delta \mathrm{S} / \mathrm{S}_{0}$ with time.

In a first step the value $\mathbf{S}_{\mathbf{0}}$ of reference is measured with a circulation of electrolyte. In a second step, the colloidal dispersion, prepared at the same $\mathrm{pH}$ and the same salt content as the former electrolyte solution, is introduced. The increase of $\mathbf{S}$ is recorded up to the steady state. Experiments are all performed at room temperature $\left(20^{\circ} \mathrm{C}\right)$ and the flow rate is typically $\mathrm{Q}=3.5 \mathrm{~cm}^{3} \mathrm{mn}^{-1}$.

Surface potential

To understand the mechanisms of approach and deposition of the particles onto the substrates, the charges of both the particles and the substrates have to be evaluated.

Concerning the nanoparticles, the important parameter is their effective charge $Z_{\text {eff }}$, which takes into account the screening of the charge by the ionic atmosphere around the particles. $Z_{\text {eff }}$ is evaluated in terms of zeta potential, defined as the potential at the shear plane. Zeta potential values of particles are obtained from electrophoretic and acoustic mobility measurements performed by using two different techniques. Laser zetametry can be performed ("NanoZs" instrument Malvern) only at low volume fraction $\Phi_{\mathrm{vol}}(\%)=10^{-2}$ because the colloidal suspensions of maghemite strongly absorb in the visible spectrum (solutions are black reddish). Using acoustophoresis ${ }^{34}$, the minimum volume fraction $\Phi_{\mathrm{vol}}(\%)=0.1 \%$ is required but there is no limitation in the high volume fraction range provided the samples are liquid $\left(\Phi_{\mathrm{vol}}(\%) \geq 0.1 \%\right.$ ). Here we use $\Phi_{\mathrm{vol}}(\%)=0.2$ (weight fraction $1 \%$ ) and the 
measurements are performed at several $\mathrm{pH}$ and ionic strength values. For our system, the zeta potential varies with the volume fraction ${ }^{35}$ (the effective charge increases when $\Phi_{\text {vol }}$ decreases) therefore the values of zeta potential obtained with acoustophoresis are lower than with laser zetametry in the same conditions of $\mathrm{pH}$ and ionic strength.

Concerning the substrates, several cases are encountered. When the charge of the substrate is intrinsic (mica) or developed by charged groups on polymeric chains adsorbed onto the substrate (mica or gold + poly-L-Lysine), the sign of the charge is well known. However, for conductive substrates like gold, the description of the interface solution / surface is more complicated. In fact, the total charge at the interface (gold / solution) can be described as the sum of a (i) protonic charge due to oxide groups exchanging protons with the solution depending on the $\mathrm{pH}$ of the medium (point of zero charge: $\mathrm{pH} \mathrm{5}$ ), (ii) of the a charge induced by specific adsorption which depends on the composition of the system (iii) of an electronic charge supplied by the external electric source; this is the so called "amphifunctional" double layer model ${ }^{36}$. The open circuit potential (OCP) is moreover sensitive to the purity of the electrolyte.

Surface potentials of mica and gold were determined in several studies by fitting AFM force-distance curves according to the DLVO theory ${ }^{36,37,38}$, and by implementing streaming potential measurements ${ }^{39}$ under specific experimental conditions. The purpose of this work is not to redefine the interface gold / solution or mica / solution under our experimental conditions, but to probe the impact of a modification of the potential applied and the impact of a chemical modification of the substrate. Consequently, values of PZC, potential values, sign of surface charge relative to gold surfaces are extracted from the literature and confronted to our experimental results.

\section{III- Results and discussion}

To probe the influence of the electrostatic interactions on the adsorption phenomenon and in particular the interactions substrate / particles, we first use a mercury drop electrode. Indeed, $\mathrm{Hg}$ is a good model system as the surface is easily perfectly reproducible and well defined. However no direct observation of the surface is possible, thus we use in a second step charged solid substrates as mica and gold. Kinetics of adsorption can be achieved at a gold electrode by implementing reflectometric measurements. AFM can be performed on both substrates and allows a direct observation of the adsorption.

\subsection{Approach near charged surfaces: electrochemical observations on the mercury electrode}

The approach of particles near charged surfaces is at first probed by the intermediate of the reactivity of the nanoparticles on the mercury electrode, i.e. of the electrochemical currents related to the conversion of the iron oxide particles. The influence of the potential is first examined in alkaline medium at low ionic strength $\left(10^{-4}\right.$ mol. $\left.\mathrm{L}^{-1}\right)$. Figure 2 shows the influence on the voltammogram of the potential $\mathrm{E}_{\mathrm{wait}}$ at which the mercury drop is prepolarized before the voltammogram. If $\mathrm{E}_{\mathrm{wait}}=-0.8 \mathrm{~V}$, no reduction occurs on the electrode, whereas if $\mathrm{E}_{\mathrm{wait}}=0 \mathrm{~V}$, a reduction and the corresponding oxidation occur. At a higher ionic strength $\left(10^{-2} \mathrm{~mol} . \mathrm{L}^{-1}\right)$, the same phenomenon is observed however the currents are higher, meaning that more particles are transformed, thus more particles approach. A systematic study is presented in Figure 3: the $\mathrm{Hg}$ is prepolarized during $\mathrm{t}_{\text {wait }}$ at several $\mathrm{E}_{\mathrm{wait}}$, then $\mathrm{E}$ is set to $-1.5 \mathrm{~V}$ in order to measure the peak corresponding to the reduction into metallic iron around $-1.7 \mathrm{~V}$. The height of the peak decreases while decreasing the potential $\mathrm{E}_{\mathrm{wait}}$ and there is no longer reduction for $\mathrm{E}_{\mathrm{wait}}<-0.55 \mathrm{~V}$. If the ionic strength is higher than $5.10^{-2} \mathrm{~mol} \mathrm{~L}{ }^{-1}$, current is detected whatever the potential of prepolarization.

Considering that the observation of current corresponds to the possible approach of the nanoparticles, it means that particles cannot always approach the electrode, depending on the potential applied to the electrode. The occurrence of the current coincides with the change of sign of the mercury surface with E, which is localized around $-0.430 \mathrm{~V}$ (vs $\mathrm{Ag} / \mathrm{AgCl}$ ) but can shift around this value while changing the nature of the electrolyte. Here the negative particles approach when the surface is positive; less and less particles approach while the charge of mercury decreases, and they do not approach if the mercury is negatively charged. This is consistent with the results of Caselli et al ${ }^{40}$, who studied the behaviour of gold nanoparticles $(\mathrm{d}=13 \mathrm{~nm}$ and $22 \mathrm{~nm})$ with an $\mathrm{Hg}$ surface, the potential of which was tuned (without electron transfer). Indeed they observed that no adsorption of these negatively charged particles took place at potential applied to mercury more negative than the P.Z.C..

A third parameter, which is not considered in the results previously presented, is the time $t_{w}$ spent at $E_{w a i t}$. Performing experiments similar to those presented in Figure 2, the current value of the reduction peak $\mathbf{B}$ increases with the waiting time $t_{w}$ spent at the potential $E_{w a i t}$ and saturate for large $t_{w}$. Moreover, after a time $t_{w}$ spent at $E>-0.5 V$, if one replaces the colloidal suspension by the electrolyte, voltammograms similar to those measured in the colloidal suspension are obtained. These observations mean that there is adsorption of the particles on the electrode.

Although there is no direct observation of the surface, the previous results seem to emphasize the strong influence of the electrostatic interaction between the particles and the surface. Nevertheless, performing the same kind of experiments in acidic medium leads to different results. The currents are very low even at highly negative potentials applied to the electrode although the positive particles should be able to reach the surface when it is negative. The currents remain also very low at high ionic strength. On the basis of these results one can wonder about the real influence of the electrostatics in the adsorption process and also about the real correlation between the measured current and the approach of the particles at the electrode.

To better understand the factors which control the approach, we thus switch to charged solid surfaces, which enable 
direct observations of the surfaces.

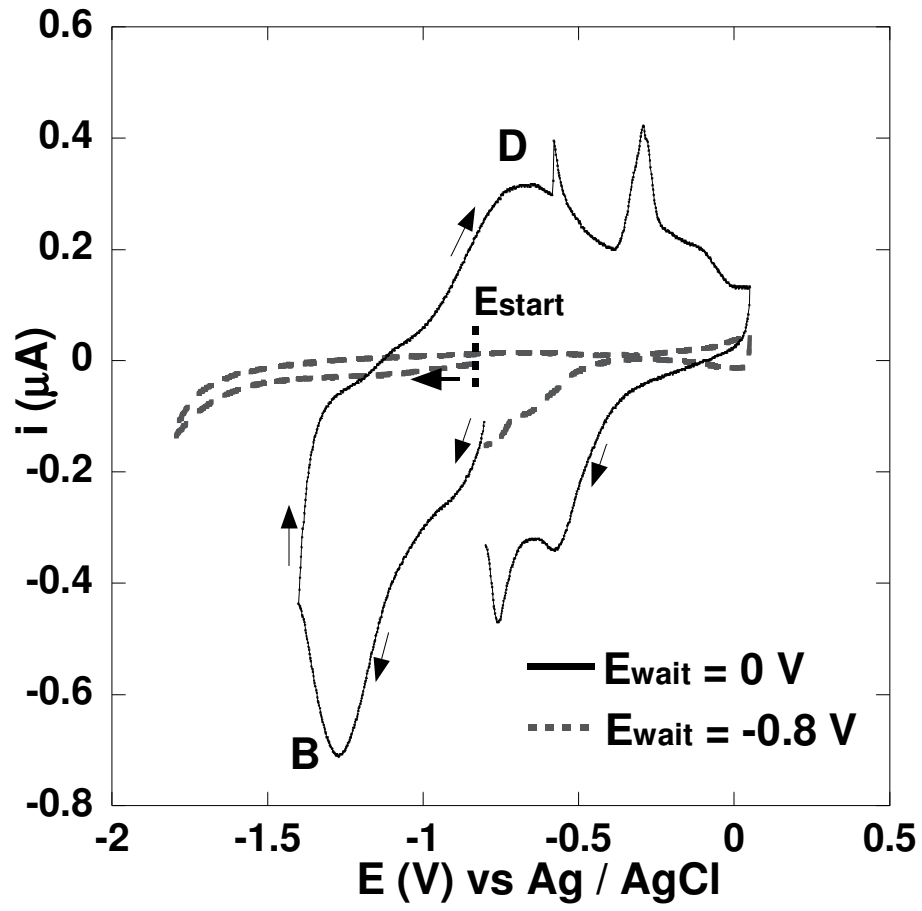

Figure 2: Hanging mercury drop electrode (HMDE): cyclic voltammograms in a suspension of iron oxide nanoparticles in a tetramethyl ammonium hydroxide solution at $\mathrm{pH}=10$ (negatively charged particles, $\Phi_{\mathrm{vol}}(\%)=10^{-3}$, [iron] $=6.10^{-4} \mathrm{~mol} \mathrm{~L}^{-1}$ ). Prior to the cycle, the mercury drop potential is maintained to a fixed value $\mathrm{E}_{\mathrm{wait}}$ during 5 minutes. The dashed line corresponds to $E_{w a i t}=-0.8 \mathrm{~V}$ and the full line to $E_{w a i t}=0 \mathrm{~V}$. The scan in potential starts at $\mathrm{E}_{\text {start }}=-0.8 \mathrm{~V}$ towards more negative values. $\mathrm{E}(\mathrm{V}) / \mathrm{Ag} / \mathrm{AgCl}$, platinum counter electrode, sweep rate: $100 \mathrm{mV} / \mathrm{s}$.

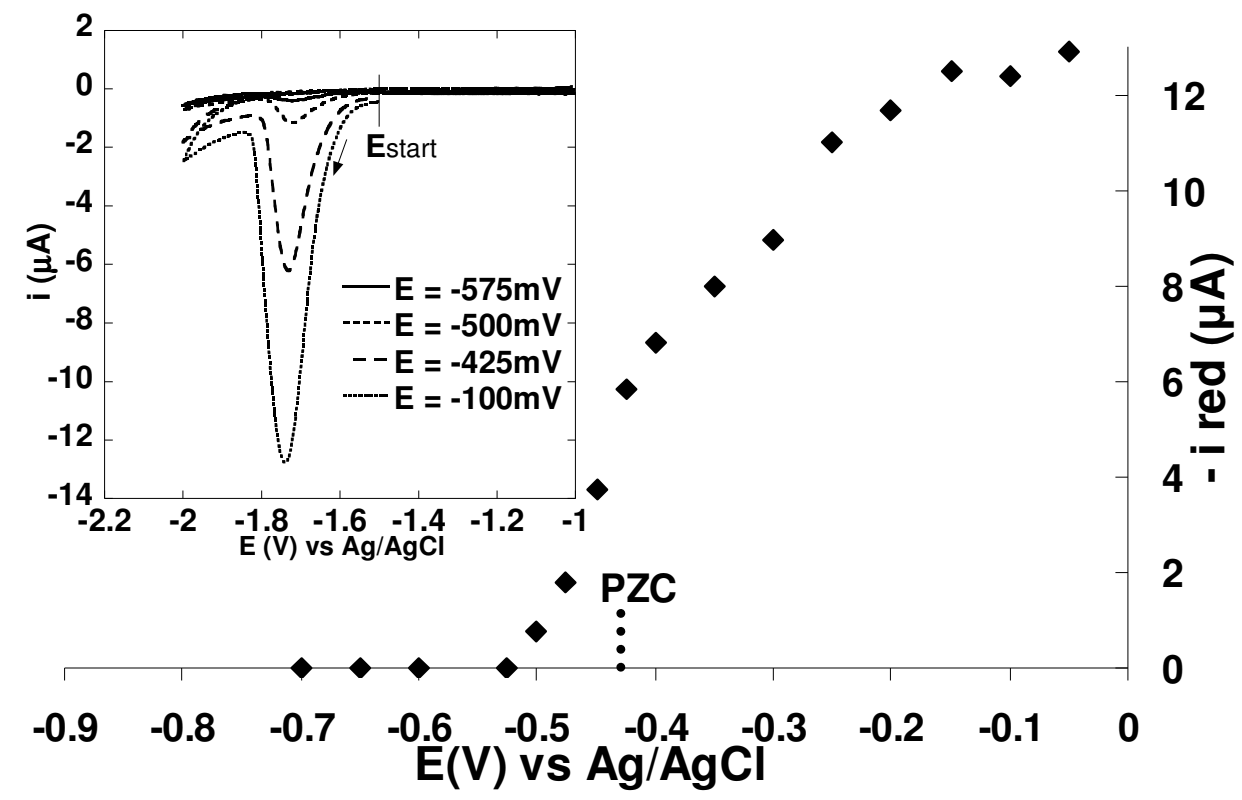

Figure 3: Cyclic voltammograms performed at a hanging mercury drop electrode in a colloidal suspension $\left(\Phi_{\mathrm{vol}}(\%)=\right.$ $0.05 \%$ ) in tetramethyl ammonium hydroxide solution at $\mathrm{pH}=12.0$ (see the inset). Just prior to cycle from $\mathrm{E}_{\text {start }}=-1.5$ $\mathrm{V}$, the electrode is polarized during $60 \mathrm{~s}$ at a fixed potential value $\mathrm{E}(\mathrm{mV})$ between $0 \mathrm{~V}$ and $-0.7 \mathrm{~V}$ vs $\mathrm{Ag} / \mathrm{AgCl}$. The peak current values $\left(i_{\text {red }}\right)$ measured at $E_{\text {peak }}=-1.75 \mathrm{~V}$, equivalent to the adsorption rate at the electrode, are plotted as a function of the electrode polarization. 


\subsection{AFM on solid substrates}

AFM measurements are used to probe the existence of adsorption on solid charged substrates and the influence of the electrostatic on the adsorption. With this purpose, two kinds of substrates are used: (i) mica, the charge of which is negative whatever the $\mathrm{pH}$ but can be turned positive for $\mathrm{pH}<10$ after a treatment with poly-L-lysine (ii) gold, a conductive substrate, the charge of which is expected, at the open circuit potential (OCP), to change from a negative to a positive charge around $\mathrm{pH}=5$ (see values in Figure $4 \mathrm{~b})^{37}$. The charges of the particles are also modified: the measurements of the zeta potential in different conditions show that the particles are indeed positively charged in acid medium and negatively charged in neutral and alkaline media (see Figure 4a and Figure 5a).

These different substrates are plunged in the colloidal suspensions at various $\mathrm{pH}$. Three conditions of $\mathrm{pH}$ are studied: 3,7 and 11. The volume fraction of the particles is the same in each case: $\Phi_{\mathrm{vol}}(\%)=10^{-3}$. No salt is added at $\mathrm{pH}=3$ and 11 whereas at $\mathrm{pH}=7$, the concentration of citrate is fixed at $10^{-2} \mathrm{~mol} \mathrm{~L}^{-1}$ allowing the colloidal stability. After 30 $\mathrm{s}$ of contact between the substrates and the colloidal suspensions, the substrates are rinsed with water. Figure $5 \mathrm{~b}$ shows an example of AFM image obtained on gold when a deposit is observed. It has been checked that there is no influence of the rinsing time on the deposits, which means that the adsorption process is irreversible. The inset of Figure $5 \mathrm{~b}$ plots the height measured along a strait line in this image, emphasizing the low roughness of the gold substrate that allows therefore to distinguish the particles adsorbed.

The results are summarized in Figure 5a. In view of the charges of both the particles and the substrates, these results show that the electrostatic interactions seem to be important in the adsorption process. In most cases, the particles do not absorb on the surfaces that present a charge of the same sign as their own charge. The only exception in Figure 5a is the case of positive particles on gold in acidic medium $(\mathrm{pH}=3)$ that adsorb although they should not as the charge of gold is expected to be positive (see Figure $4 b$ ).

However, in this experiment, the $\mathrm{pH}$ of 3 may not be far enough from the point of zero charge $(\mathrm{pH}=5)^{37}$, so that the charge of gold may not be high enough to avoid the adsorption of the particles, the other interactions being still dominating. Moreover, positive particles adsorb on positive substrates when the ionic strength increases (on both modified gold and mica for $\mathrm{I}>10^{-2} \mathrm{~mol} \mathrm{~L}^{-1}$ ), which means that electrostatic interactions are screened, whereas the negative particles still do not adsorb on negative substrates whatever the ionic strength. This shows the strong influence of other interactions than the electrostatic ones on the adsorption process.

\begin{tabular}{|c|c|c|c|c|c|}
\hline$\zeta(\mathrm{mV})$ vs pH & pH 2 & pH 3 & $\begin{array}{c}\text { pH 3 } \\
\mathrm{I=10} 0^{-2} \mathrm{M}\end{array}$ & $\begin{array}{c}\mathrm{pH} \mathrm{7} \\
\mathrm{I}=\mathbf{1 0}^{-2} \mathrm{M}\end{array}$ & $\mathrm{pH} \mathrm{12}$ \\
\hline Laser zeta metry & 29 & 39 & 31 & -35 & -40 \\
\hline Acoustophoresis & 22 & 28 & 20 & -30 & -35 \\
\hline
\end{tabular}

a)

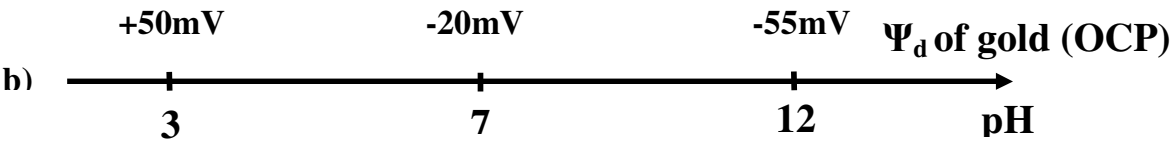

Figure 4: a) zeta potential values of iron oxide nanoparticles for different $\mathrm{pH}$ (adjusted by $\mathrm{HClO}_{4}$ ) and ionic strengthes (adjusted by $\mathrm{NH}_{4} \mathrm{ClO}_{4}$ ) using laser zetametry and acoustophoresis. b) double layer potential of a bare gold electrode at the open circuit potential (OCP: $+150 \mathrm{mV}$ vs $\mathrm{Ag} / \mathrm{AgCl}$ ) in $\mathrm{KCl} 1 \mathrm{mmol} \mathrm{L}^{-1}$ (Giesber and al ${ }^{39}$ ) or $\mathrm{KNO}_{3} 1 \mathrm{mmol} \mathrm{L}^{-1}$ $\left(\right.$ Barten and $\left.\mathrm{al}^{37}\right)$. 


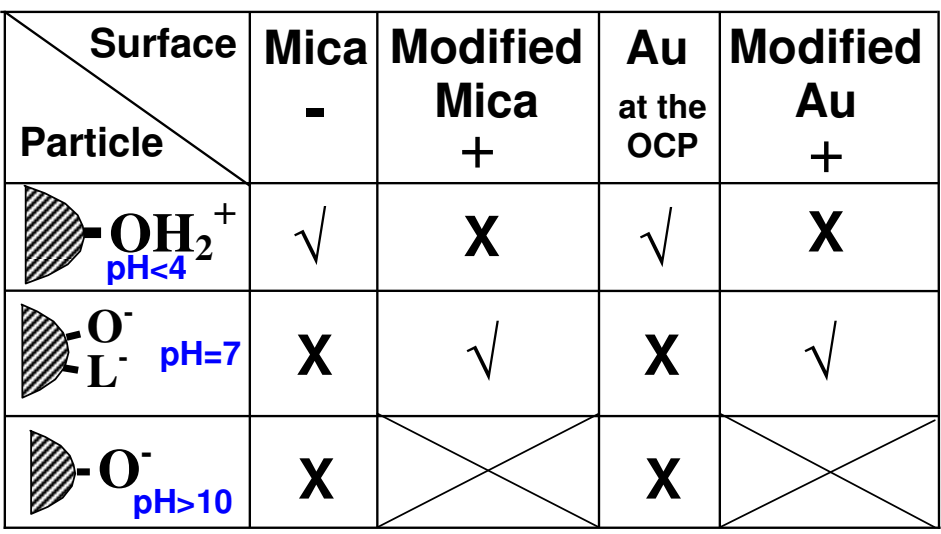

a)

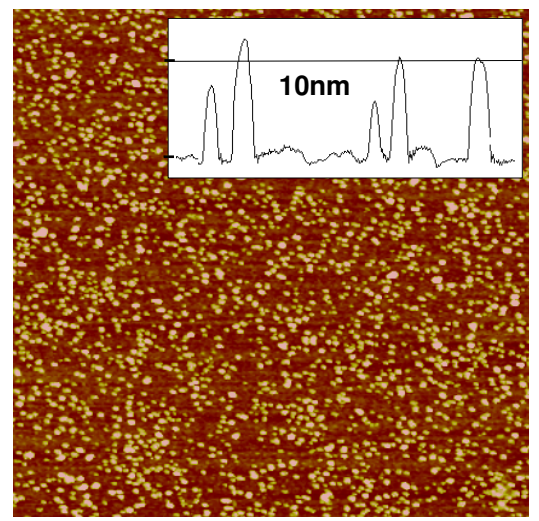

b)

Figure 5: a) Results obtained by AFM measurements for the deposition of particles on the substrates in different conditions. The charge of the substrate is indicated. Modified substrate signifies modified by poly-L-lysine leading to positive charge. For gold at the OCP, the charge is given in Figure $4 b$. Symbol $(\mathbf{X})$ : no deposit, Symbol $(\sqrt{ })$ : existence of a deposit. b) Image AFM $(3 \mu \mathrm{m} \times 3 \mu \mathrm{m})$ of particles deposited onto ultra flat gold surfaces at the OCP. The inset plots the height measured along a line in this image.

\subsection{Electrochemical measurements in colloidal suspension}

With the aim of studying more precisely the influence of electrostatic interactions on the approach and the adsorption, we determine the kinetics of deposition under different conditions of ionic strength, $\mathrm{pH}$, and potential applied to the electrode. AFM alone is not suitable for that purpose (see §2.2). Moreover AFM probes the presence of particles adsorbed whereas electrochemical measurements probe the fact that particles approach the electrodes. Therefore, the question is to know if the approach is always followed by adsorption, so if the electrochemical currents are correlated to the adsorption. Here we use the gold substrate which allows us to couple complementary techniques. AFM images and electrochemical measurements allow us to correlate the current and the presence of adsorbed particles; reflectometry allows us to check the kinetics determined with the electrochemical measurements.

Let us examine the case of a gold electrode dipped into an acidic colloidal suspension $\left(\mathrm{HClO}_{4}\right)$. A voltammogram on the whole electroactivity domain at $\mathrm{pH}=3$ is plotted in the inset of Figure $6 \mathrm{a}$. In the voltammogram performed at $\mathrm{pH}=$ 2 , the same peaks are observed, however the reduction of $\mathrm{H}^{+}$limits the domain and only the interval $[-0.6 ;+0.9$ $\mathrm{V} / \mathrm{SCE}$ ] can be explored. Figure $6 \mathrm{a}$ shows voltammetric cycles at $\mathrm{pH}=2$ for increasing times $\mathrm{t}$ spent at the OCP before scanning. Three main peaks appear. Note that the two symmetric peaks around $+0.5 \mathrm{~V}$ only appear if potentials below $0.1 \mathrm{~V} / \mathrm{SCE}$ have been previously scanned. For these three peaks, the current increases with $\mathrm{t}$, as already observed on $\mathrm{Hg}$ (see §3.1) and saturates for long times. On the same timescale, parallel AFM measurements show an increase of the amount of adsorbed particles.

To check if the current originates from the particles, $\mathrm{FeSO}_{4}$ is added. As ionic iron is also in solution, the current results from both contribution of ionic iron and of the particles. The addition of $\mathrm{FeSO}_{4}$ destabilizes the colloidal suspension due to $\mathrm{SO}_{4}{ }^{2-}$ ions, thus after a waiting time, the particles sediment and can no longer reach the electrode. These two first cycles then measured are plotted in Figure 6b. The first cycle shows peaks at the same potential as those observed on the voltammogram of reference obtained directly in the colloidal suspension (voltammogram at $t=5$ min of Figure 6a). However, the two peaks around $+0.5 \mathrm{~V} / \mathrm{SCE}$ are much higher. During the second cycle, the two peaks are still observed whereas the peak at $-0.18 \mathrm{~V}$ has disappeared. Consequently, the current at $-0.18 \mathrm{~V}$ in cycle 1 must correspond to particles already adsorbed on the electrode and the absence of current at $-0.18 \mathrm{~V}$ in cycle 2 means that the whole electroactive material at the electrode has been transformed.

When $\mathrm{FeSO}_{4}$ is added to the suspension, the intensity of the peaks at $+0.5 \mathrm{~V} / \mathrm{SCE}$ associated to the ions $\mathrm{Fe}^{\mathrm{III}} / \mathrm{Fe}^{\mathrm{II}}$ is very important. These peaks are also observed when only nanoparticles are present ( the current measured with nanoparticles is lower than with ions even if the concentration of iron are the same in both case), this means that ferrous ions are formed at $-0.18 \mathrm{~V}$, which corresponds to the dissolution of the particles in acidic medium. This point is confirmed by AFM measurements on ultra flat gold surfaces ${ }^{2}$.

In all conditions presented in Figure 5a, electrochemical currents and a signal in reflectometry are only measured when particles are observed with AFM. Therefore, there is a systematic correlation between a signal in reflectometry, a current in electrochemistry and a deposit in AFM. This means that these currents only occur when the particles adsorb at the electrode. Moreover, as the current increases with time as the number of adsorbed particles observed with AFM, one can suppose that the electrochemical current due to the reduction of the nanoparticles is proportional to the number of nanoparticles deposited on the surface. In the following, an electrochemical method allowing to study the kinetics of deposition of the particles onto a gold electrode under conditions where adsorption occurs, is presented. 

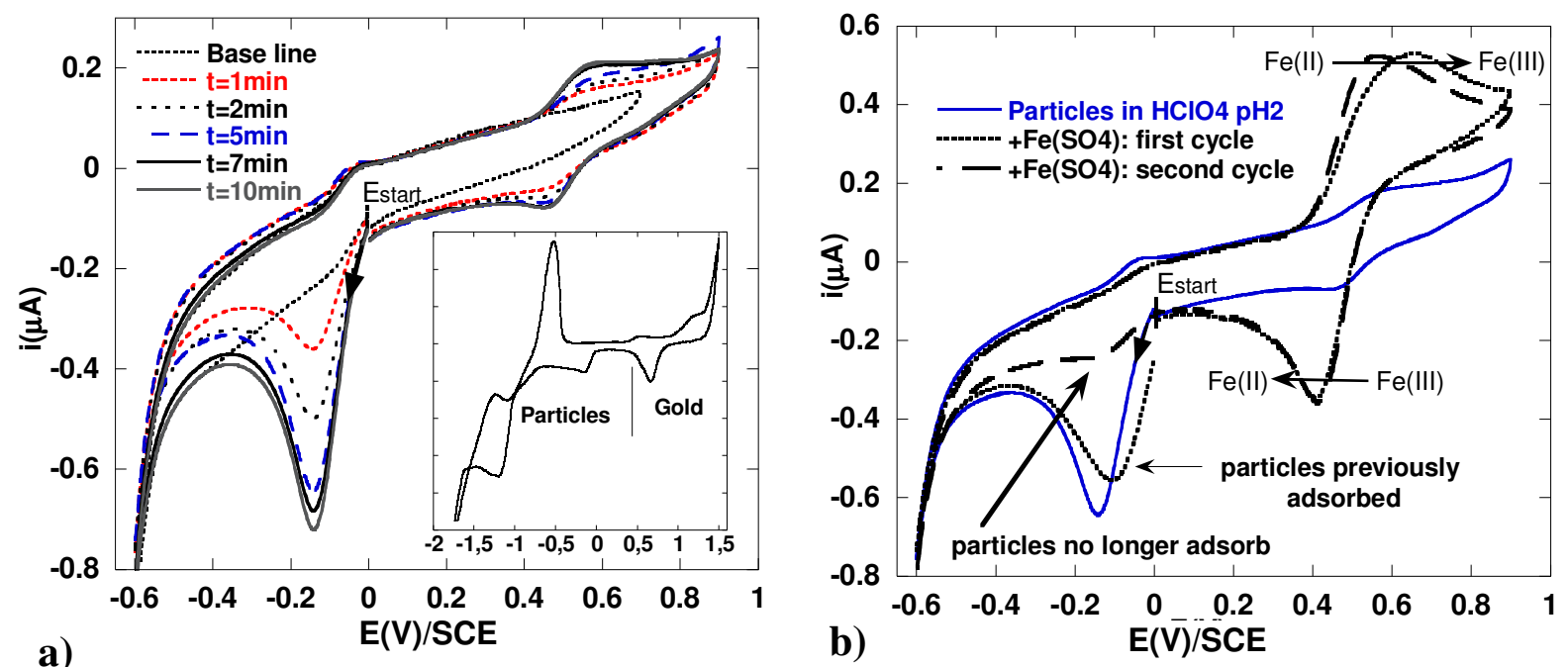

Figure 6: Cyclic voltammetry performed in $\mathrm{HClO}_{4}$ at $\mathrm{pH}=2.0$ on a polycrystalline gold electrode (scan rate: $100 \mathrm{mV}$ $\left.\mathrm{s}^{-1}, \mathrm{E}(\mathrm{mV}) / \mathrm{SCE}\right)$ a) before (base line) and after addition of iron oxide nanoparticles $\left(10^{-3} \%,[\mathrm{Fe}]=6.410^{-4} \mathrm{~mol} \mathrm{~L}^{-1}\right)$ : the electrode is maintained at the open circuit potential during increasing times $\mathrm{t}$ before cycling from $0 \mathrm{~V}$ to negative potential values. The inset: voltammogram performed in $\mathrm{HClO}_{4}$ at $\mathrm{pH}=3$ on the whole electroactivity domain b) Full line (blue): voltammogram of Figure $6 \mathrm{a}$ with $\mathrm{t}=5 \mathrm{~min}$. Dotted and dashed black lines: First and second cycle after addition of $\mathrm{FeSO}_{4}$ to the suspension $\left([\mathrm{Fe}]=6.410^{-4} \mathrm{~mol} \mathrm{~L}^{-1}\right)$ leading to the precipitation of the suspension.

\subsection{Kinetics of deposition onto gold surfaces: Influence of the $\mathrm{pH}$ and the ionic strength.}

The kinetics of deposition of the particles onto gold under different conditions of $\mathrm{pH}$ and of ionic strength allows to probe the impact of the electrostatic interactions on the adsorption. By using the electrochemical method, the current measured results from both the particles adsorbed before scanning the potential and the new adsorbed particles. In fact, the adsorption process goes on during the reduction process in the colloidal suspension. In order to separate these two contributions and to control the deposition process, we implement an original method that makes profitable the irreversible adsorption of the particles onto the electrode. First, deposition of particles onto gold is achieved by plunging the substrate into the colloidal suspension during a fixed time either at the open circuit potential (O.C.P) or at a fixed potential value. Second, the substrate is rinsed in the electrolyte that is later used for voltammogram to eliminate the particles not yet adsorbed. Voltammetric measurements are performed in a supporting electrolyte without any particles. To compare the currents related to the electrochemical conversion of particles throughout all experiments, the concentration and the nature of the electrolyte is maintained the same.

In the case of positive particles in acidic medium, voltammetry can be implemented either at $\mathrm{pH}=2$ or at $\mathrm{pH}=3$. At $\mathrm{pH}=2$, only the peak of dissolution at $-0.18 \mathrm{~V} / \mathrm{SCE}$ can be observed because the domain of electroactivity is restricted due to the proton reduction. At $\mathrm{pH}=3$, the peak at $-0.18 \mathrm{~V} / \mathrm{SCE}$ is small (the dissolution depends on the $\mathrm{pH}$ ) and it is more convenient to focus on the peak at $-1.2 \mathrm{~V} / \mathrm{SCE}$ to study the kinetics. Following this last procedure $\Delta \mathrm{i}_{\text {red }}=\left(\mathrm{i}_{\text {peak }}{ }^{-\mathrm{i}_{\text {base }}}\right.$ line) extracted from cyclic voltammograms is plotted versus time in Figure 7a. The current first increases linearly with time up to saturation. The same profile is obtained with reflectometry measurements realized under similar conditions. As the signal in reflectometry is proportional to the amount of adsorbed particles, it proves that the saturation of the reductive current corresponds to a limitation of the amount of particles deposited and not of the electron transfer. Note that the timescale differs in reflectometry and electrochemistry due to the different hydrodynamic conditions during the deposition. As a flow rate is imposed in reflectometry the plateau is reached after shorter times than in electrochemistry.

The profile of the kinetics can be explained by considering that there are two regimes depending on the time scale (short or long times). In the early steps of deposition of particles, when a few particles are adsorbed, their adsorption depends on the interactions between the substrate and the particles. At long times, when the coverage of the surface becomes important, wandering particles undergo mainly the influence of the interactions with the particles already adsorbed. As these interactions are repulsive electrostatic interactions, they hinder the adsorption of new particles, which leads to a saturation. By changing the conditions of $\mathrm{pH}$ and ionic strength of the colloidal suspension, the resulting modification in the charge and the magnitude of both the substrate and the particles should influence the deposition process. In the following we shall study the influence of $\mathrm{pH}$ and I on the kinetics deposition. In this system, the colloidal concentration is very low $\left(10^{-5} \mathrm{~mol} \mathrm{~L}^{-1}\right)$ compared with the ionic concentration. When the $\mathrm{pH}$ is fixed with $\mathrm{HClO}_{4}$ at $\mathrm{pH}=1, \mathrm{pH}=2$ or $\mathrm{pH}=3$ and when no salt is added to the suspension, we assume that $\mathrm{H}^{+}$and $\mathrm{ClO}_{4}{ }^{-}$are 
in excess and play the role of the ionic atmosphere of the colloid. Thus, in this special case the $\mathrm{pH}$ determines the ionic strength.

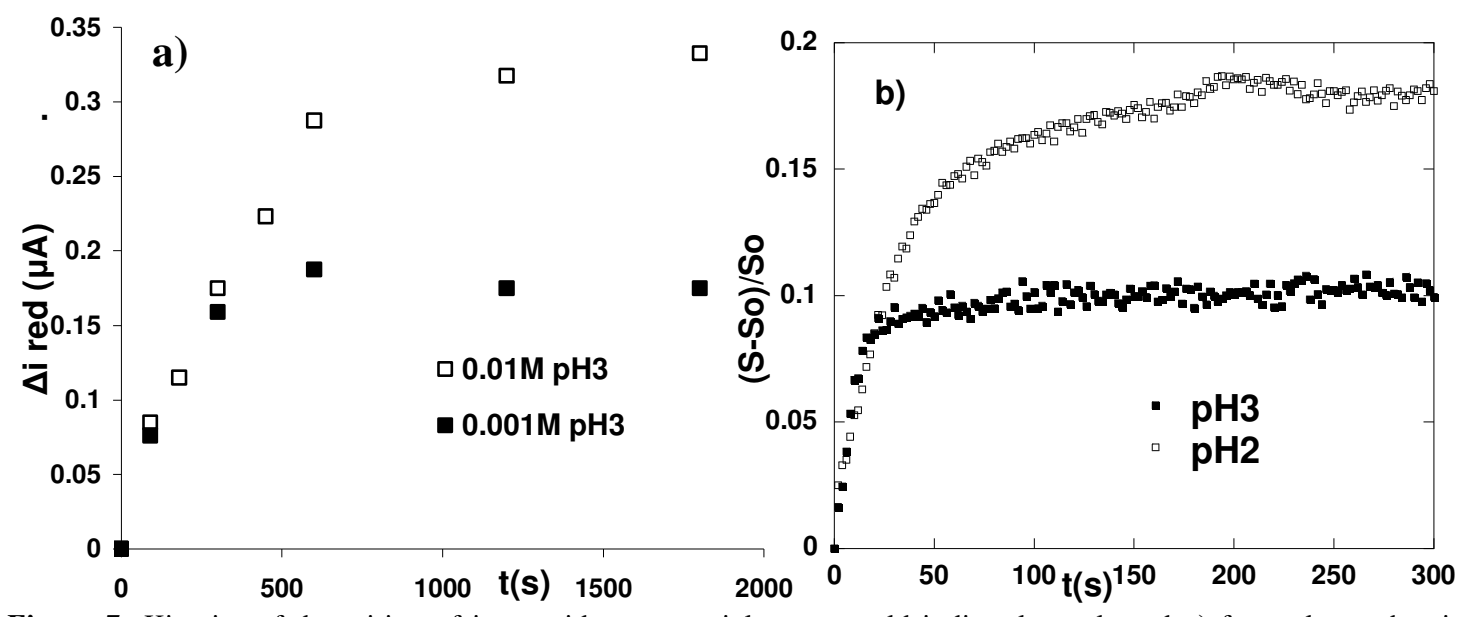

Figure 7: Kinetics of deposition of iron oxide nanoparticles onto gold indirectly evaluated a) from electrochemical measurements after deposition onto gold in a colloidal suspension $\left(\Phi_{\mathrm{vol}}=10^{-3} \%\right.$ ) diluted in $\mathrm{HClO}_{4} \mathrm{pH}=3.0$ (black squares) and $\mathrm{HClO}_{4} \mathrm{pH}=3.0+\mathrm{NH}_{4} \mathrm{ClO}_{4} 0.01 \mathrm{~mol} \mathrm{~L}^{-1}$ (open squares), b) by reflectometry measurements at $\mathrm{pH}=2.0$ (open squares) and 3.0 (black squares) $\left(\Phi_{\mathrm{vol}}=2.810^{-3} \%\right)$.

\subsubsection{Initial deposition}

Applying the electrochemical techniques, kinetics at $\mathrm{pH}=3$ and kinetics at $\mathrm{pH}=3$ with added salt leading to an ionic strength of $10^{-2} \mathrm{~mol} \mathrm{~L}^{-1}$ are performed (Figure 7a). Note that it is difficult to measure a significant current for very short times $(\mathrm{t}<30 \mathrm{~s})$, because it corresponds to deposition of only a few particles, and because the protocol introduces inaccuracies on the determination of the time of deposition t. Figure 7a shows no difference on the initial slopes of the two kinetics. Using reflectometry, kinetics at $\mathrm{pH}=3$ and $\mathrm{pH}=2\left(\mathrm{I}=10^{-2} \mathrm{~mol} \mathrm{~L}^{-1}\right.$, no salt added) are performed (see Figure $7 b$ ). At short times, which are easily accessed with this technique, the identical initial slopes are identical whatever the conditions. Both electrochemical and reflectometry demonstrate that there is no influence of the modification of the interactions between the particles and the substrate. This result is confirmed by additional experiments exploring the influence of the potential applied on gold during the deposition (the applied potential is limited to values that do not lead to electrochemical transformations). Indeed, in acidic medium, the potential applied (E > - $0.2 \mathrm{~V} / \mathrm{SCE}$ ) has no influence on the amount of positive particles adsorbed onto gold, although the charge of gold is expected to increase with $\mathrm{E}$. This result is in good agreement with the observation of Roques-Carmes on positively charged poly(vinylimidazol) ${ }^{22}$ onto gold: the polymers adsorb even at high E. In alkaline medium, the negative particles never come to the electrode for $\mathrm{E}>0 \mathrm{~V} / \mathrm{SCE}$, although the charge of the electrode is expected to be positive $\left(\mathrm{PZC}=-0.3 \mathrm{~V} / \mathrm{SCE}\right.$ in $\left.\mathrm{TMAOH}^{41}\right)$. Consequently, electrostatic interactions between the particles and the gold substrates have a weak influence on the initial deposition.

\subsubsection{Saturation}

After the initial steps of deposition, for longer times, the available surface on the substrate becomes smaller and the "wandering particles" undergo the influence of the electrostatic interactions with the already adsorbed particles. The deposition process slows down and finally reaches a maximum which depends on the ionic strength (Figure 7). Indeed, the range of the repulsive interactions increases when the ionic strength decreases because the effective radius $\mathrm{a}_{\mathrm{eff}}$ of the particles defined as the size of the particles plus the range of the interactions, increases. Therefore, at $\mathrm{pH}=3$, the coverage obtained is lower than at the same $\mathrm{pH}$ with added salt (Figure 7a), and than at $\mathrm{pH}=2$ (Figure $7 \mathrm{~b}$ ). The similarity of the shapes of the curves in Figure $7 \mathrm{a}$ (electrochemistry) and Figure $7 \mathrm{~b}$ (reflectometry) validates the electrochemical method.

At the saturation step, it is difficult to predict the structure of the deposits with a method of observation like reflectometry which gives a result averaged with respect to the probed surface. Only an imaging technique would be suitable for such an observation, however AFM is no longer suitable when coverage is greater than a few percents. Indeed the coverage becomes too high to be precisely determined. Nevertheless, the coverage is greater than $10 \%$, which is the maximal coverage measurable. At $\mathrm{pH}<2$, AFM shows that the whole surface is covered, but does not allow to know if particles adsorb as multilayer, however the surface exhibits a high roughness that could correspond to aggregates. Conversely, at $\mathrm{pH}=3$ just a few aggregates occur and particles essentially deposit as monolayer.

By using the approach of Semmler ${ }^{12,18}$, already applied to other different systems, it is possible to predict the maximal coverage $\theta_{\max }$. In this model, the size polydispersity of particles is not taken into account, and once adsorbed the particles can not move. With the radius of the particles and the ionic strength as input parameters in the calculation, it 
is possible first to determine the Debye length $\kappa^{-1}$ and an approximate effective charge $Z_{\text {eff }}$, then to calculate the potential of interaction and the distance between the particles, and therefore to deduce $\theta_{\max }$. The maximal coverage obtained with hard spheres (without interaction) in the framework of this model is $\theta_{\max }=54.7 \%$ (the jamming limit obtained with a random sequential adsorption $\left.{ }^{42}\right)$. For $\mathrm{a}=6 \mathrm{~nm}$ and $\mathrm{pH}=3\left(\mathrm{I}=10^{-3} \mathrm{~mol} \mathrm{~L}^{-1}\right)$, the theoretical coverage at saturation is $\theta_{\max }=2.8 \%$.

Experimentally, after a deposition of maghemite nanoparticles at $\mathrm{pH}=3$ on mica substrate, the coverage at saturation is estimated to be about $10 \%$ (note that the determination of the amount of adsorbed particles by AFM is not accurate: see experimental part). Similar results are found on gold surfaces. Our observations by AFM measurements differ from those of Kooij et $\mathrm{al}^{20}$, who succeeded in measuring coverage about $20 \%$ with particles of similar size. This difference could be inherent to the different nature of the substrates and of the particles (gold nanoparticles, silicon substrates derivatized with APTES). Nevertheless, in a general way, the coverage obtained at saturation with our system and others ${ }^{12}$ are greater than theoretical ones. This discrepancy, especially marked for low ka values, could be related to the overestimation of $\mathrm{Z}_{\mathrm{eff}}$ by the use of a model that is not suitable. It could also be due to the size polydispersity of the particles or to their diffusion on the surface after adsorption.

In order to better identify the parameters governing the value of the maximal coverage, we implement electrochemical measurements on a gold electrode since AFM can not be used. The effects of the ionic strength and of the $\mathrm{pH}$ are distinguished by first performing the deposition in colloidal suspensions under various conditions of $\mathrm{I}$ or $\mathrm{pH}$, in acidic medium $(\mathrm{pH} \leq 3)$ and at constant volume fraction. Then the electrochemical measurements are conducted in the same supporting electrolyte at $\mathrm{pH}=3$ throughout all experiments.

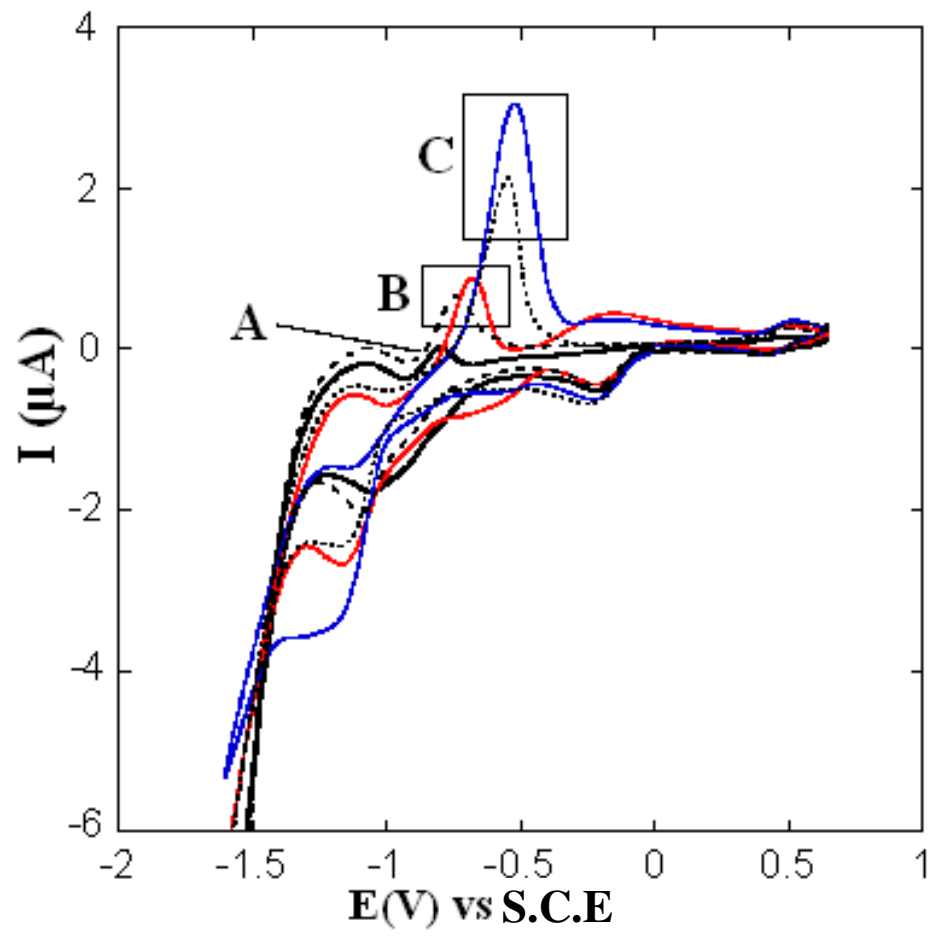

Figure 8: Cyclic voltammograms in $\mathrm{HClO}_{4} 10^{-3} \mathrm{~mol} \mathrm{~L}^{-1}$ of iron oxide particles (positively charged) adsorbed onto polycrystalline gold electrode. The electrode is plunged during 5 minutes at the open circuit potential in colloidal solutions at different $\mathrm{pH}$ and ionic strength values (I) and then rinsed just prior to cycle with: A) $\left.\mathrm{I}=10^{-3} \mathrm{~mol} \mathrm{~L}^{-1}, \mathbf{B}\right) \mathrm{I}$ $\left.=10^{-2} \mathrm{~mol} \mathrm{~L}^{-1}, \mathbf{C}\right) \mathrm{I}=10^{-1} \mathrm{~mol} \mathrm{~L}^{-1}$.

- $\left[\mathrm{H}^{+}\right]$effect: A): (Full black line) $\mathrm{HClO}_{4} 10^{-3} \mathrm{~mol} \mathrm{~L}^{-1}(\mathrm{pH}=3.0)$, B): (Full red line) $\mathrm{HClO}_{4} 10^{-2} \mathrm{~mol} \mathrm{~L}-1(\mathrm{pH}=2.0)$, C): (Full blue line) $\mathrm{HClO}_{4} 10^{-1} \mathrm{~mol} \mathrm{~L}^{-1}(\mathrm{pH}=1.0)$.

- $\left[\mathrm{NH}_{4}^{+}\right]$effect: B): (Dashed line) $\mathrm{NH}_{4} \mathrm{ClO}_{4} 10^{-2} \mathrm{~mol} \mathrm{~L}^{-1}, \mathrm{pH}=3.0\left(\mathrm{HClO}_{4} 10^{-3} \mathrm{~mol} \mathrm{~L}{ }^{-1}\right)$, C): (Dotted line) $\mathrm{NH}_{4} \mathrm{ClO}_{4}$ $10^{-1} \mathrm{~mol} \mathrm{~L}^{-1}, \mathrm{pH}=3.0$.

In the voltammogram plotted in Figure 8, we compare the well defined oxidation peaks of the particles that correspond to the oxidation of metallic iron previously formed around $\mathrm{E}=-1.3 \mathrm{~V} / \mathrm{SCE}$ by reduction of the particles. Different ionic strengths are compared, either by adjusting the $\mathrm{pH}$ without any addition of salt, or by adjusting the concentration of salt at constant $\mathrm{pH}$.

The current, which is representative of the amount of particles adsorbed at the electrode, increases with the ionic strength. That confirms the results obtained in Figure 7. Nevertheless, a systematic effect appears: the current is always greater when the ionic strength is exclusively controlled by $\mathrm{HClO}_{4}$. Let us see if this difference can be 
explained in term of electrostatic interactions. This interaction, which depends on the structural charge $Z_{b}$ of the particle and on the ionic strength, can be estimated from the zeta potential measurements. Moreover, it seems difficult to estimate $Z_{\text {eff }}$ a priori since $Z_{b}$ depends on the $\mathrm{pH}$ (see $\$ 2.1$ ) and also on the ionic strength ${ }^{30}$. Therefore we use zeta potential values measured in various conditions in order to estimate $Z_{\text {eff }}$.

The values of zeta potential at $\mathrm{pH}=2$ with only $\mathrm{H}^{+}$ions and $\mathrm{pH}=3$ with added salt $\left(10^{-2} \mathrm{~mol} \mathrm{~L}^{-1}\right)$ are very close (Figure 4a) and much lower than $\zeta(\mathrm{mV})$ at $\mathrm{pH}=3$. Moreover, at $\mathrm{I}=10^{-1} \mathrm{~mol} \mathrm{~L}^{-1}\left(\mathrm{pH}=1\right.$ or $\mathrm{pH}=3+$ salt $\left._{10}^{-1} \mathrm{~mol} \mathrm{~L}^{-1}\right)$, the $\zeta(\mathrm{mV})$ values, which can be only obtained by acoustophoresis, are much lower than the previous ones (they are around $10 \mathrm{mV})$. Thus, the decrease of $\zeta(\mathrm{mV})$, related to the increase of I, explains the higher screening of the repulsive interactions and therefore the increase of the coverage at saturation. However, the zeta potential values do not allow us to understand the difference in the current measured depending on the way the ionic strength is adjusted $\left(\mathrm{HClO}_{4}\right.$ or $\mathrm{NH}_{4} \mathrm{ClO}_{4}$ ).

This difference could be related to a modification of the particles (hydrolysis) once deposited onto the gold surface, which was observed by Raman spectroscopy ${ }^{2}$. Their surface being modified, the particles may bear a surface charge different from the particles in solution, leading to a lower intensity of the electrostatic interactions and therefore to a higher coverage. This hydrolysis is important at $\mathrm{pH}=1$, but it becomes less and less pronounced when the $\mathrm{pH}$ increases.

\section{Conclusion}

In this study, we investigated the approach of charged nanoparticles (maghemite $\left(\gamma-\mathrm{Fe}_{2} \mathrm{O}_{3}\right)$ near charged substrates (mercury and gold electrodes) before their electrochemical conversions. Under defined conditions, when particles are able to come very close to the electrode, they adsorb onto its surface due to short range interactions (van der Waals). We showed that the adsorption process of the particles is irreversible. We also observed a systematic correlation between the occurrence of an electrochemical current when a scan in potential is applied and the presence of particles adsorbed at the surface of the electrode revealed by AFM measurements. If no electrochemical current is measured, no adsorbed particles are observed with AFM, therefore particles are not able to approach to the surface of the electrode. According to the nature of the substrate (gold, mica, mercury) and the $\mathrm{pH}$ of the medium, the role of the electrostatic interactions between the substrate and the particles in the adsorption process is variable. In a general way, neither adsorption nor current on metallic substrates occur when the electrostatic interactions between particles and substrates are both not favourable to the approach of the particles and are long ranged (at low ionic strength).

When adsorption occurs under appropriate conditions, it is possible to evaluate the amount of particles adsorbed from the current associated to their electrochemical transformation and thereby to access kinetics of deposition of the particles. The determination of which is important to understand the parameters that govern the adsorption of the particles. These electrochemical measurements correlated to reflectometry showed that the electrostatic interactions between the particles and the gold substrates play a minor role in the adsorption process. Conversely, the repulsive electrostatic interactions between the particles already adsorbed and the "wandering particles" near the electrodes are crucial, they limit the amount of particles that can adsorb onto the electrode and thereby the electrochemical current. The coverage of the electrode therefore depends on the range of the electrostatic interactions according to the conditions of $\mathrm{pH}$ and ionic strength of the colloidal suspensions. The electrochemical measurements emphasize that the effect of the $\mathrm{pH}$ on the coverage at saturation is more marked than the effect of the ionic strength although zetametry did not reveal any evident change in the charge of the particles. We interpret this difference in term of a chemical modification of the particles in acidic medium in contact with the gold electrode. Indeed a phenomenon of hydrolysis occurs at the surface of the particle that could explain its adsorption in acidic medium. Thanks to the results obtained, the deposition of the particles (kinetics and coverage at saturation) onto charged substrates can now be controlled and, in a second step, allows studying the electrochemical transformations of such nanomaterials.

\section{Acknowledgment}

The authors thank Doctor C. Filiâtre and Professor F. Membrey of the university of Franche-Comté (France) for performing reflectometric measurements on gold substrates. 


\section{Notes and references}

${ }^{a}$ Université Pierre et Marie Curie-Paris6, Laboratoire Liquide Ionique et Interfaces Chargées,UMR CNRS 7612,case courrier 51, 4 place Jussieu, F75005 Paris 5, France.

*ivlucas@ccr.jussieu.fr

1 E. Dubois and J. Chevalet, Langmuir, 2003, 19, 10892.

2 I. T. Lucas, E.Dubois, J. Chevalet, S. Durand-Vidal and S. Joiret, Reactivity of nanocolloidale particles $\gamma$-Fe2O3 at the charged interface: 2 Electrochemical conversion. Submitted to PCCP.

3 Z. Adamczyk, Particles at Interfaces; Interface Science and Technology vol 9, Elsevier, 2006.

4 Z. Adamczyk, M. Zembala, B.Siwek and J. Czarnecki, J. Colloid Interface Sci., 1986, 110, 188.

5 N. Ryde, N. Kallay and E. J. Matijevic, Chem. Soc. Faraday Trans., 1991, 87, 1377.

6 B. Vincent, C. A. Young T. F. J.Tadros, Chem. Soc. Faraday I, 1980, 76, 665.

7 J.C. Dijt, M. A. Cohen Stuart, J. E. Hofmann and G. J. Fleer, J. Colloid Interface Sci., 1990, 51, 141.

8 C. A. Johnson and A. M. Lenhoff, J. Colloid and Interface Sci., 1996, 179, 587.

9 P. F. Luckham and J. Klein, Chem. Soc. Trans. I, 1984, 80, 865.

10 Z. Adamczyk, B.Siwek, P.Warszynski and E. Musial, J. Colloid Interface Sci., 2001, 242,14.

11 Z. Adamczyk, Adv. Colloid and Interface Sci., 2003, 100-102, 267.

12 M. Semmler, E.K. Mann, J. Ricka and M.Borkovec, Langmuir, 1998, 14, 5127

13 S. Harlay, D. W. Thompson and B. Vincent, Colloids Surf., 1992, 62, 163.

14 R. A. Hayes, M. R. Bohmer and L. G. J. Fokkink, Langmuir 1999, 15, 2865.

15 M. R. Böhmer, E. A. van der Zeeuw and G. J. M. Koper, J. Colloid and Interface Sci., 1998, 197, 242.

16 T. Dabros and T. G. M. van de Ven, Colloid and Polymer Sci., 1983, 261, 694.

17 C. A. Johnson and A. M. Lenhoff, J. Colloid Interface Sci. 1996, 179, 587.

18 M. Semmler, J.Ricka and M. Borkovec, Coll. Surf. A, 2000, 165, 79.

19 Y. Yuan, M. R. Oberholzer and A. M. Lenhoff, Coll. Surf. A, 2000, 165, 125.

20 E. S. Kooij, E. A. M. Brouwer, H. Wormeester and B. Poelsema, Langmuir, 2002, 18, 7677.

21 E. A. M. Brouwer, E. S. Kooij, H. Wormeester and B. Poelsema, Langmuir, 2003, 19, 8102.

22 T. Roques-Carmes, F. Membrey, A. Deratani, M. R. Böhmer and A. Foissy, J. Colloid and Interface Sci., 2002, $256,273$.

23 N. G. Hoogeveen, M.A. Cohen Stuart and G. J. Fleer, J. Colloids and Interface Sci., 1996, 182, 133.

24 R. C. van Duijvenbode, G. J. M. Koper and M. R. Böhmer, Langmuir, 2000, 16, 7713.

25 E. A. M. Brouwer, E. S. Kooij, M. Hakbijl, H. Wormeester and B. Poelsema, Coll. Surf. A, 2005, 267, 133.

26 D. Barten, J. M.Kleijn and M. A. Cohen Stuart, Phys. Chem. Chem. Phys., 2003, 5, 4258.

27 J. M. Kleijn, D. Barten and M. A. Cohen Stuart, Langmuir, 2004, 20, 9703.

28 R. Massart and V. Cabuil, J. Chim. Phys. 1987, 84, 967.

29 R. Massart, E. Dubois, V. Cabuil and E. Hasmonay, J. Magn. Magn. Mat, 1995, 149, 1.

30 I. T. Lucas, S. Durand-Vidal, E. Dubois, J. Chevalet and P.Turq, Surface charge density of maghemite nanoparticles: Role of electrostatics in the proton exchange. J. Phys. Chem C: accepted

31 E. Dubois, V. Cabuil, F. Boué and R. Perszinski, J. Chem. Phys., 1999, 111, 7147.

32 J. C. Dijt, M. A. Cohen-Stuart, J. E. Hofman and G. J. Fleer, Colloids Surf. 1990, 51, 141.

33 F. Membrey, C. Filiatre, I. T. Lucas, E. Dubois, Chevalet, J. and S. Durand-Vidal, forthcoming publication.

34 A. S. Dukhin and P. J.Goetz; Ultrasound for characterizing colloids, Studies in interface science vol 15, series editors Möbius D. and Miller R., Elsevier (2002).

35 I. T. Lucas, S. Durand-Vidal, E. Dubois, G. Roger, V. Dahirel, M. Jardat, J.-F. Dufrêche, O.Bernard, G. Meriguet and P. Turq., Effective charge in colloidal suspensions: example of maghemite nanoparticles: in preparation.

36 J. Duval, J. Lyklema,; J. M. Kleijn and H. P. van Leeuwen, Langmuir, 2001, 17, 7573.

37 D. Barten, J. M. Kleijn, J. Duval, H. P. van Leeuwen, J. Lyklema, and M. A. Cohen-Stuart, Langmuir, 2003, 19, 1133.

38 J. Wang and A. J. Bard, J. Phys. Chem. B., 2001, 105, 5217.

39 M. Giesbers, J. M. Kleijn and M. A. Cohen-Stuart, J. Colloid and Interface Sci., 2002, 248, 88.

40 M. Caselli, G.Lippolis and L. Gierst, J. Electroanalytical Chemistry 1972, 38, 451.

41 A. Tymosiak-Zielinlska, and Z. Borkowska, Electrochimica Acta, 2000, 45, 3105.

42 B. Senger, J.-C. Voegel and P. Schaaf, Colloids and Surfaces A 2000, 165, 255. 